\title{
Pulmonary Manifestations in von Recklinghausen's Disease
}

Von Recklinghausen's disease, neurofibromatosis type 1 (NF1), is a common autosomal disorder characterized by multiple neurofibromas, café au lait spots, and Lisch nodules of the iris with a variable clinical expression. This disorder appears to affect all races, with a prevalence estimated to be 1 in 3,000 live births. The NF1 gene is located in 17q11.2. However, due to the high mutation rate at the NF1 locus, most patients are expected to have different mutations (1-3).

Lung involvement in NF1 is a well-known complication, and it consists of diffuse interstitial fibrosis and bullae, either alone or in combination. The interstitial fibrosis characteristically involves both lungs symmetrically with some basal predominance, whereas the bullae usually are asymmetric and tend to develop in the upper lobes (4). However, histological examination has revealed that the fibrosis is seen in all patients with bullae. Estimated incidences of interstitial fibrosis have ranged from 7 to 10 percent $(5,6)$. Even though the NF1 gene has already been discovered, it is not clear whether the NF1 locus is also responsible for the lung involvement.

In this issue, a 48-year-old man with NF1 (von Recklinghausen's disease) who presented with distal acinar emphysema and interstitial pneumonia is reported (7).

\section{See also $\mathrm{p} 413$.}

Distal acinar emphysema is recognized as one of the three subcategories of emphysema (8): centriacinar, panacinar and distal acinar. It is usually focal and consists of small emphysematous spaces in a more or less continuous zone of variable length located in the periphery of the lung adjacent to the pleura or along interlobular septa. Since distal acinal emphysema, in contrast to the other types, is generally thought to be not closely related to smoking history, coexistence of this type of emphysema and fibrosis in the patient leads to the speculation that distal acinar emphysema may be a unique manifestation of smoking-induced lung injury in a case of NF1. The authors in this paper also reported that smoking cessation suppressed the decline of pulmonary function during the 5-year follow-up period. This beneficial effect of smoking cessation seen in this patient suggests some connection of distal acinal emphysema and smoking in this particular case. These findings may indicate that the repair process for smoking-induced lung injury is somehow genetically determined. It remains to be seen how the effect of smoking on lung injury involvement appear in a case of NF1.

It is important to note that pulmonary manifestation in cases of NF1 seems to be a mixture of interstitial fibrosis and emphysema. The two disorders are generally considered to be separate. Each has distinguished clinical, radiological, physi- ological and pathological characteristics. Both disorders are at some stage associated with inflammation. Many researchers have focused on the inflammatory process in the formation of both emphysema and fibrosis, such as protease, and oxygen radicals. There has been another view that they simply represent different manifestations in response to the same lung injury. Niewoehner and Hoidal (9), indeed, demonstrated that cadmium chloride, administered intratracheally to golden hamsters, causes an acute lung injury which develops into diffuse fibrosis. However, with simultaneous feeding of a lathyroge, beta-aminoproprionitrile, this cadmium chloride-induced lung injury evolves into bullous emphysema. They concluded the same lung injury might result in either fibrosis or emphysema, during the healing phase being the critical determinant. If this hypothesis is true in the lung involvement in NF1, the healing process might be somehow genetically determined.

If the repair process to some lung injury is genetically determined, the lung involvement in NF1 would serve as a good model where one can investigate the mechanisms behind such a variable repair process for smoking-induced lung injury.

Kenji Miyamoto, MD The Department of Physical Therapy, College of Medical Technology, Hokkaido University, N-15, W-5, Kita-ku, Sapporo 060

\section{References}

1) Lazaro C, Gaona A, Ravella A, Volpini V, Casals T, Fuentes JJ, Estivill $\mathrm{X}$. Novel alleles, hemizygosity and deletions at an Alu-repeat within the neurofibromatosis type 1 (NF1) gene. Hum Mol Genet 2: 725, 1993.

2) Reyniers E, De Boulle K, Marchuk DA, Andersen LB, Collins FS, Willems PJ. An EcoRI RFLP in the 5' region of the human NF1 gene. Hum Genet 92: 631, 1993.

3) Shen MH, Harper PS, Upadhyaya M. Molecular genetics of neurofibromatosis type 1 (NF1). J Med Genet 33: 2, 1996.

4) Massaro D, Katz S. Fibrosing alveolitis: Its occurrence, roentgenographic and pathologic features in von Recklinghausen's neurofibromatosis. Am Rev Respir Dis 93: 934, 1966.

5) Burkhalter JL, Morano JU, McCay MB. Diffuse interstitial lung disease in neurofibromatosis. South Med J 79: 944, 1986.

6) Webb WR, Goodman PC. Fibrosing alveolitis in patients with neurofibromatosis. Radiology 122: 289, 1977.

7) Yokoyama A, Kohno N, Sakai K, Kondo K, Hirasawa Y, Hiwada K. Distal acinar emphysema and interstitial pneumonia in a patient with von Recklinghausen's disease: five-year observation following quitting smoking. Intern Med 36: 413, 1997.

8) Official statement of the American Thoracic Society. Standard for the diagnosis and care of patients with chronic obstructive pulmonary disease and asthma. Am Rev Respir Dis 143: 225, 1986.

9) Niewoehner DE, Hoidal JR. Lung fibrosis and emphysema: Divergent responses to a common injury? Science 217: 359, 1982. 